\title{
Familial Hemiplegic Migraine
}

\author{
Daniela Pietrobon
}

Department of Biomedical Sciences, University of Padova, 35121 Padova, Italy

\begin{abstract}
Summary: Familial hemiplegic migraine (FHM) is a rare and genetically heterogeneous autosomal dominant subtype of migraine with aura. Mutations in the genes CACNA1A and $S C N A 1 A$, encoding the pore-forming $\alpha_{1}$ subunits of the neuronal voltage-gated $\mathrm{Ca}^{2+}$ channels $\mathrm{Ca}_{\mathrm{V}} 2.1$ and $\mathrm{Na}^{+}$channels $\mathrm{Na}_{\mathrm{V}} 1.1$, are responsible for FHM1 and FHM3, respectively, whereas mutations in ATP1A2, encoding the $\alpha_{2}$ subunit of the $\mathrm{Na}^{+}, \mathrm{K}^{+}$adenosinetriphosphatase (ATPase), are responsible for FHM2. This review discusses the functional studies of two FHM1 knockin mice and of several FHM mutants in heterologous expression systems (12 FHM1, 8 FHM2, and 1 FHM3). These studies show the following: (1) FHM1 mutations produce gain-of-function of the $\mathrm{Ca}_{\mathrm{v}} 2.1$ channel and, as a consequence, increased $\mathrm{Ca}_{\mathrm{v}} 2$.1-dependent neurotransmitter release from cortical neurons and facilitation of in vivo induction and propagation of cortical spreading depression (CSD: the phe-
\end{abstract}

nomenon underlying migraine aura); (2) FHM2 mutations produce loss-of-function of the $\alpha_{2} \mathrm{Na}^{+}, \mathrm{K}^{+}$-ATPase; and (3) the FHM3 mutation accelerates recovery from fast inactivation of $\mathrm{Na}_{\mathrm{V}} 1.5$ (and presumably $\mathrm{Na}_{\mathrm{V}} 1.1$ ) channels. These findings are consistent with the hypothesis that FHM mutations share the ability of rendering the brain more susceptible to CSD by causing either excessive synaptic glutamate release (FHM1) or decreased removal of $\mathrm{K}^{+}$and glutamate from the synaptic cleft (FHM2) or excessive extracellular $\mathrm{K}^{+}$(FHM3). The FHM data support a key role of CSD in migraine pathogenesis and point to cortical hyperexcitability as the basis for vulnerability to CSD and to migraine attacks. Hence, they support novel therapeutic strategies that consider CSD and cortical hyperexcitability as key targets for preventive migraine treatment. Key Words: Migraine, cortical spreading depression, $\mathrm{Ca}^{2+}$ channel, $\mathrm{Na}^{+}, \mathrm{K}^{+}$ATPase, $\mathrm{Na}^{+}$channel, epilepsy.

\section{INTRODUCTION}

Migraine is a common episodic headache disorder affecting more than $10 \%$ of the general population. It is characterized by unilateral and pulsating moderate-tosevere headache (lasting 4 to 72 hours), often accompanied by nausea, phonophobia, and photophobia (migraine without aura, MO), that may be preceded by transient (usually less than 60 minutes) neurological symptoms, that are most frequently visual but may involve other senses (migraine with aura, MA). Migraine arises from a primary brain dysfunction that leads to activation and sensitization of the trigeminovascular system; the nature and mechanisms of this primary brain dysfunction are incompletely understood. ${ }^{1,2}$ Migraine has a strong (up to 50\%) genetic component (higher in MA than MO), with a likely multifactorial polygenic inheritance. ${ }^{3,4}$

Familial hemiplegic migraine (FHM) is a rare autosomal dominant subtype of MA, whose aura symptoms include

Address correspondence and reprint requests to: D. Pietrobon, Dept. Biomedical Sciences, University of Padova, V.le G. Colombo 3, 35121 Padova, Italy; E-mail: daniela.pietrobon@unipd.it. motor weakness or paralysis (often, but not always, unilateral). Apart from the obligatory motor aura, typical FHM attacks resemble MA attacks. Nearly always, at least three, and often four, aura symptoms are present in FHM (typically in the temporal order: visual, sensory, motor, aphasic), and they last longer than in MA. MA usually has only visual symptoms but the appearance and progression of the visual symptoms are similar in MA and FHM. Also, the duration of the headache is usually longer in FHM than MA, but all other headache characteristics are similar. ${ }^{5}$ FHM and MA attacks may alternate in patients and cooccur within FHM families, and compared with the general population FHM probands have an almost eight times increased risk of MA, ${ }^{6}$ suggesting that FHM and MA may be part of the same spectrum and may share some pathogenetic mechanisms. The study of FHM mechanisms may thus provide unique insights into the pathophysiology of migraine.

In addition to typical FHM attacks, some FHM patients can have atypical severe attacks with signs of diffuse encephalopathy, impairment of consciousness (coma) or confusion, prolonged hemiplegia lasting several days, and in a few cases seizures. ${ }^{7,8}$ Moreover, about $20 \%$ of FHM fam- 


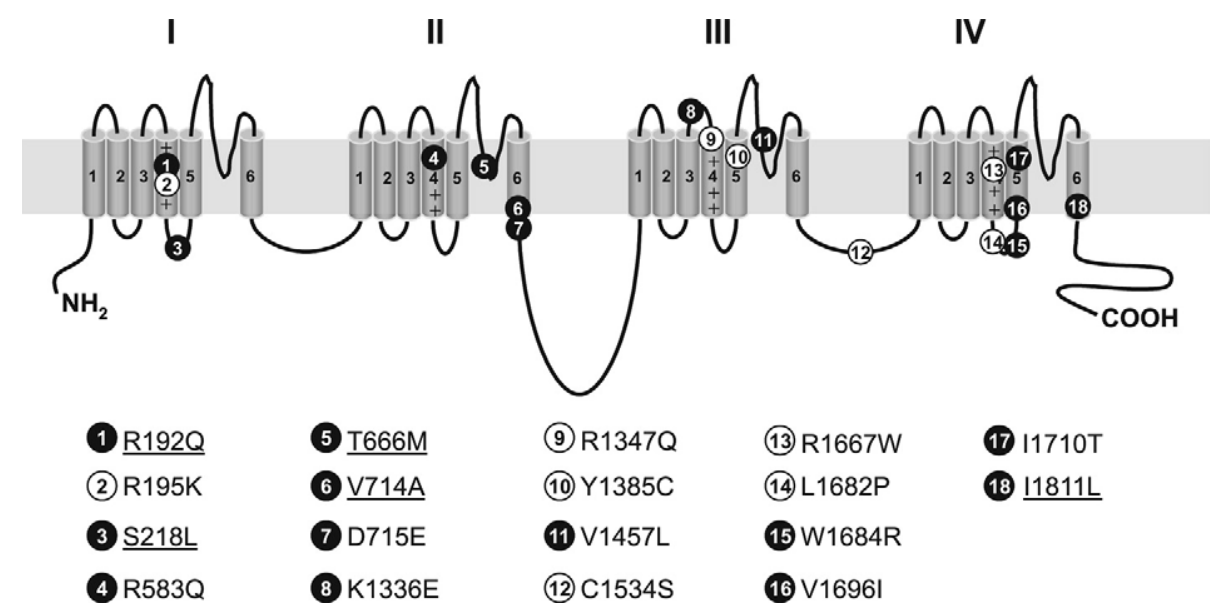

FIG. 1. Secondary structure of the $\mathrm{Ca}_{\mathrm{v}} 2.1 \alpha_{1}$ subunit and location of the familial hemiplegic migraine 1 mutations identified so far. In black: mutations whose functional consequences have been studied in heterologous expression systems. Underlined: mutations whose functional consequences have been studied also in transfected neurons from $\mathrm{Ca}_{\mathrm{v}} 2.1^{-/-}$mice.

ilies show permanent cerebellar symptoms consisting of progressive cerebellar ataxia with or without nystagmus. ${ }^{5}$ Emotional stress and minor head trauma are among the most common triggers of FHM attacks. ${ }^{7,8}$

FHM is genetically heterogeneous. Mutations in the genes CACNA1A at chromosome 19p13 (see Ophoff et al. ${ }^{9}$ ), ATP1A2 at $1 \mathrm{q} 23$ (see De Fusco et al. ${ }^{10}$ ), and SCNA1A at $2 \mathrm{q} 24$ (see Dichgans et al. ${ }^{11}$ ) are responsible for type 1 (FHM1, up to $50 \%$ of the cases), type 2 (FHM2, 20\% to $30 \%$ of the cases), and type 3 FHM (FHM3), respectively. Clinically, there are few differences in symptoms between the genetically different types of FHM, except for the cerebellar symptoms that are almost exclusively associated with FHM1.

Sporadic hemiplegic migraine (SHM) has clinical characteristics identical to FHM, but without other affected cases in the family. Some of the SHM patients are the first FHM patients, as shown by the identification of CACNAIA mutations in three of about 40 patients analyzed; however, SHM patients exist without mutations in known FHM genes. ${ }^{12}$ Most linkage and association studies indicate that the CACNA1A and ATP1A2 genes are not involved in MA (see Kirchmann et al., ${ }^{13}$ Netzer et al.., ${ }^{14}$ and references therein). However, missense mutations in the ATP1A2 gene have been identified in two families with clustering of common forms of migraine ${ }^{15}$ and in a family with basilar migraine, a subtype of MA in which the aura symptoms originate from the brainstem or reflect simultaneous involvement of both hemispheres. ${ }^{16}$

\section{FAMILIAL HEMIPLEGIC MIGRAINE TYPE 1 (FHM1)}

The FHM1 gene, CACNA1A, was identified in 1996; CACNAIA encodes the pore-forming $\alpha_{1}$ subunit of the neuronal voltage-gated calcium channel $\mathrm{Ca}_{\mathrm{V}} 2.1$ (or P/Qtype $\mathrm{Ca}^{2+}$ channel). ${ }^{9}$ This subunit consists of four re- peated domains (I-IV) each of which contains six transmembrane regions (S1-S6) comprising a voltage sensor $\mathrm{S} 4$ and a pore loop between S5 and S6 ${ }^{17}$ (compare Cannon ${ }^{18}$ and FIG. 1). Eighteen different missense mutations associated with FHM1 have been described, including the Y1385C SHM mutation ${ }^{19,20}$ (FIG. 1). All produce substitutions of conserved amino acids in important functional regions including the pore lining and the voltage sensors. Pure FHM1 and FHM1 with cerebellar symptoms are associated with distinct mutations. ${ }^{7}$ Symptom variability among subjects with the same mutation suggests that other genetic or environmental factors also influence the phenotype.

$\mathrm{Ca}_{\mathrm{V}} 2.1$ channels are located in presynaptic terminals and somatodendritic membranes throughout the brain, where they play a prominent role in controlling neurotransmitter release particularly at central excitatory synapses. $^{21}$ The somatodendritic localization of $\mathrm{Ca}_{\mathrm{V}} 2.1$ channels points to additional postsynaptic roles; e.g., in neural excitability. $\mathrm{Ca}_{\mathrm{v}} 2.1$ channels are expressed in all brain structures that have been implicated in the pathogenesis of migraine, including the cerebral cortex, the trigeminal ganglia, and brainstem nuclei involved in the central control of nociception. ${ }^{1}$ Their expression is particularly high in the cerebellum. Deletion of the $\mathrm{Ca}_{\mathrm{v}} 2.1 \alpha_{1}$ mouse gene leads to severe cerebellar ataxia and dystonia together with selective progressive cerebellar degeneration. ${ }^{22,23}$ Different mouse strains with spontaneous $\mathrm{Ca}_{\mathrm{v}} 2.1 \alpha_{1}$ mutations all suffer from ataxia and exhibit reduced $\mathrm{P} / \mathrm{Q}$-type current in Purkinje cells. ${ }^{24}$ Moreover, null $\mathrm{Ca}_{\mathrm{v}} 2.1^{-/-}$mice and the majority of the spontaneous mutants harboring loss-of-function mutations in $\mathrm{Ca}_{\mathrm{v}} 2.1$ show absence seizures. ${ }^{21,24}$ A $50 \%$ loss of $\mathrm{Ca}_{\mathrm{v}} 2.1$ channels leads to reduced responses to inflammatory and neuropathic pain in heterozygous $\mathrm{Ca}_{\mathrm{v}} 2.1^{-/+}$ mice, revealing an important role of these channels in 
central sensitization. ${ }^{25}$ The complex neurological phenotype of the loss-of-function $\mathrm{Ca}_{\mathrm{v}} 2.1$ mutants suggests that the lack (or reduced number and [or] functional impairment) of $\mathrm{Ca}_{\mathrm{v}} 2.1$ channels cannot be functionally compensated for at many central synapses.

In humans, mutations in the CACNAIA gene cause, in addition to FHM1, a few autosomal dominant neurological disorders characterized by cerebellar dysfunction, such as episodic ataxia type 2 (that may be associated with absence epilepsy in a few cases) and spinocerebellar ataxia type $6^{9,26,27}$ (compare, Strupp ${ }^{28}$ and $\mathrm{Gomez}^{29}$ ). Functional studies of the effects of these mutations on recombinant $\mathrm{Ca}_{\mathrm{V}} 2.1$ channels in heterologous expression systems have revealed a loss of channel function in the case of mutations causing episodic ataxia type 2 (with or without absence epilepsy) ${ }^{21}$ (compare, Strupp ${ }^{28}$ ), and conflicting effects in the case of mutations causing spinocerebellar ataxia type 6 (compare, Gomez ${ }^{29}$ ).

The functional consequences of 12 FHM1 mutations (in black, FIG. 1) have been investigated in heterologous expression systems expressing recombinant $\mathrm{Ca}_{\mathrm{V}} 2.1$ channels $^{30-36}$ (and our unpublished observations). Because $\mathrm{Ca}_{\mathrm{v}} 2.1$ channel expression is almost exclusively restricted to neuronal cells, five of these mutations (underlined in FIG. 1) have also been investigated in neurons from $\mathrm{Ca}_{\mathrm{V}} 2.1^{-1-}$ mice expressing human $\mathrm{Ca}_{\mathrm{V}} 2.1 \alpha_{1}$ subunits. $^{31,35,37,38}$ Recently, the generation of knockin mice carrying two different FHM1 mutations (R192Q and S218L) allowed the first analysis of mutant channels expressed at their endogenous level in neurons. ${ }^{39-41}$

The studies in heterologous expression systems showed that the FHM1 mutations alter many biophysical properties of human $\mathrm{Ca}_{\mathrm{V}} 2.1$ channels, in a complex way. In some cases (e.g., in the case of the channel inactivation properties) the effects were different depending on the mutation. However, an important consistent effect was revealed by studying the single channel properties of eight mutant human $\mathrm{Ca}_{\mathrm{v}} 2.1$ channels. All the FHM1 mutants showed an enhanced single channel $\mathrm{Ca}^{2+}$ influx in a wide range of mild depolarizations, reflecting an increased channel open probability, mainly due to a shift to lower voltages of channel activation ${ }^{31,34,35}$ (and our unpublished observations). Consistent (and in the majority of cases significant) shifts to lower voltages of current activation of human FHM1 mutants were also revealed by measurements of whole-cell currents in heterologous expression systems, transfected neurons and neurons of FHM1 knockin mice. ${ }^{30,31,34-36,39-41}$

The $\mathrm{Ca}_{\mathrm{V}} 2.1$ current density in cerebellar granule cells and cortical pyramidal neurons of R192Q and S218L knockin mice was larger than in wild-type neurons for a wide range of mild depolarizations. Similar current densities were measured with strong depolarizations (eliciting maximal channel open probability) indicating a similar number of functional $\mathrm{Ca}_{\mathrm{v}} 2.1$ channels in the membrane of knockin and wild-type neurons. ${ }^{39-41}$ The shift to lower voltages of $\mathrm{Ca}_{\mathrm{v}} 2.1$ channel activation and the gain-of-function of the neuronal $\mathrm{Ca}_{\mathrm{v}} 2.1$ current were about twice as large in homozygous compared with heterozygous S218L KI mice, revealing an allele-dosage effect consistent with dominance of the mutation in FHM1 patients. ${ }^{41}$

While the R192Q mutation produces a pure FHM phenotype characterized by typical attacks, the S218L mutation produces a severe clinical phenotype, in which typical attacks of FHM triggered by minor head trauma are frequently followed by deep coma or profound stupor (sometimes preceded by a generalized seizure), fever, and long-lasting severe cerebral edema; other common symptoms are ataxia and cerebral and (or) cerebellar atrophy. ${ }^{42-44}$ Accordingly, while the homozygous R192Q knockin mice appear healthy, the homozygous S218L mice are prone to sudden death for seemingly unknown reasons (probably due to severe seizures) and are ataxic (Arn van den Maagdenberg, personal communication). Compared with the other FHM1 mutations analyzed, $\mathrm{S} 218 \mathrm{~L}$ is one of the mutations that produces the largest shift of activation of human $\mathrm{Ca}_{\mathrm{v}} 2.1$ channels and the largest gain-of-function especially for small depolarizations. ${ }^{31,35}$ Accordingly, at low voltages close to the threshold of activation of mutant channels, the gainof-function of the $\mathrm{Ca}_{\mathrm{V}} 2.1$ current was larger in S218L KI mice than in R192Q KI mice. ${ }^{39,41}$

The changes in whole-cell $\mathrm{Ca}_{\mathrm{V}} 2.1$ current density in neurons from knockin mice were very similar to the changes in single channel $\mathrm{Ca}^{2+}$ influx of mutant recombinant human $\mathrm{Ca}_{\mathrm{V}} 2.1$ channels, indicating that FHM1 mutations produce a similar gain-of-function of $\mathrm{Ca}^{2+}$ influx through mouse and human $\mathrm{Ca}^{2+}$ channels. The analysis of mutant channels in neurons of knockin mice revealed that FHM1 mutations produce gain of function of $\mathrm{Ca}_{\mathrm{V}} 2.1$ channels at both the single channel and wholecell level. By contrast, varying and conflicting results were obtained from previous measurements of the whole-cell $\mathrm{Ca}^{2+}$ current in transfected neurons and HEK293 cells overexpressing mutant human $\mathrm{Ca}_{\mathrm{v}} 2.1$ channels. While either an increase or a decrease of the whole cell $\mathrm{Ca}_{\mathrm{V}} 2.1$ current density elicited by strong depolarizations was measured in HEK293 cells depending on the FHM1 mutant analyzed ${ }^{31,34,35}$ (and our unpublished observations), a consistent decrease was measured in neurons..$^{31,35,37,38}$ The R192Q mutation decreased the current density at high voltages in transfected neurons but increased it in transfected HEK293 cells. ${ }^{31,34,37,38}$ Because the same mutation did not affect the whole-cell $\mathrm{P} / \mathrm{Q} \mathrm{Ca}{ }^{2+}$ current density elicited by strong depolarizations in neurons of knockin mice expressing $\mathrm{Ca}_{\mathrm{V}} 2.1$ channels at their endogenous level, the changes in transfected cells likely reflect changes in the number of functional channels in the membrane that might be an artifact 
of overexpression. One may therefore obtain misleading answers using transfected cells to study the effect of ion channel mutations on cellular functions that depend on the number of functional channels in the membrane. This is well illustrated by the different conclusions regarding the effect of FHM1 mutations on neurotransmitter release that are reached when neurotransmission is studied in knockin mice or using transfected neurons.

The FHM1 knockin mice showed increased neurotransmission at the neuromuscular junction in conditions of low release probability (evoked release at low $\mathrm{Ca}^{2+}$ and spontaneous release). ${ }^{39,45,46}$ Moreover, recent investigation of excitatory neurotransmission at physiologic $\mathrm{Ca}^{2+}$ concentrations in microcultures of cortical neurons revealed an increased glutamate release due to an increased contribution of $\mathrm{P} / \mathrm{Q} \mathrm{Ca}^{2+}$ channels. ${ }^{47}$ In contrast, synaptic transmission was unaltered and the contribution of $\mathrm{P} / \mathrm{Q} \mathrm{Ca}^{2+}$ channels in controlling release was decreased at synapses between hippocampal neurons transfected with human R192Q $\mathrm{Ca}_{\mathrm{v}} 2.1 \alpha 1$ subunits. ${ }^{37}$

The functional studies just described lead to the important conclusion that FHM1 mutations produce gainof-function of human neuronal $\mathrm{Ca}_{\mathrm{v}} 2.1$ channels. Mutant human $\mathrm{Ca}_{\mathrm{v}} 2.1$ channels open at lower voltages and more readily than WT channels, and $\mathrm{Ca}^{2+}$ influx through mutant channels can occur in response to small depolarizations insufficient to open WT channels. As a consequence, FHM1 mutations produce gain-of-function of $\mathrm{Ca}_{\mathrm{V}} 2.1$-dependent neurotransmitter release at synapses where the presynaptic $\mathrm{Ca}^{2+}$ sensor controlling release is not saturated.

Neuroimaging findings indicate that migraine aura is due to cortical spreading depression (CSD), a wave of sustained strong neuronal depolarization, that slowly progresses across the cortex, generating a transient intense spike activity that is followed by long-lasting neural suppression. ${ }^{1}$ In animals, CSD can be induced by focal stimulation (electrical, mechanical, or with high $\mathrm{K}^{+}$) of the cerebral cortex, by inhibition of the $\mathrm{Na}^{+} / \mathrm{K}^{+}$ ATPase and by other stimuli. ${ }^{48}$ In animal studies, CSD can activate the meningeal trigeminal nociceptive afferents and evoke alterations in the meninges and brainstem consistent with the development of headache. ${ }^{49}$ Moreover, a series of known antimigraine prophylactic drugs have the common property of elevating the stimulation threshold for induction of CSD after protracted administration. ${ }^{50}$ These studies support the idea that CSD may initiate migraine attacks. ${ }^{1,2,51}$

Interestingly, FHM1 knockin mice are more susceptible to CSD than wild-type mice. In both R192Q and S218L knockin mice, gain-of-function of $\mathrm{Ca}_{\mathrm{V}} 2.1$ channels lead to a lower threshold for CSD induction and an increased velocity of propagation of CSD induced by electrical stimulation of the visual cortex in vivo. ${ }^{39,41} \mathrm{In}$ correlation with the more severe clinical phenotype of the S218L mutation, the facilitation of CSD (especially its rate of propagation) was larger in S218L than R192Q KI mice. Moreover, S218L knockin mice showed a much higher incidence of recurrent CSDs. ${ }^{41}$ The unique combination of a particularly low threshold of activation and slow inactivation, and a particularly fast rate of recovery from inactivation of mutant $\mathrm{S} 218 \mathrm{~L} \mathrm{Ca} \mathrm{Ca}_{\mathrm{V}} 2.1$ channels, probably underlie the high incidence of repetitive CSDs. ${ }^{35}$ Recurrent CSDs might open the blood-brain barrier $^{52,53}$ and explain the delayed cerebral edema and severe clinical phenotype of the S218L mutation. The facilitation of CSD induction and propagation were about twice as large in homozygous compared with heterozygous S218L KI mice, an allele-dosage effect consistent with dominance of the mutation in FHM1 patients. ${ }^{41}$ These findings support a key role of CSD in the pathogenesis of FHM1.

Together with previous CSD data from the spontaneous Cacnala mutants leaner and tottering, ${ }^{54}$ the CSD data from FHM1 knockin mice also support a key role of $\mathrm{Ca}_{\mathrm{v}} 2.1$ channels in the initiation and propagation of CSD. Loss-of-function of $\mathrm{Ca}_{\mathrm{v}} 2.1$ channels in leaner and tottering mice leads to a higher threshold for CSD induction, a lower velocity of propagation, and a shorter duration of the CSD depolarization in vivo. ${ }^{54}$ Similar inhibitory effects on CSD initiation, propagation, and duration were produced in vivo by NMDA antagonists in a dose-dependent manner. ${ }^{55}$ Moreover, a decrease in intracortical glutamate was measured by in vivo microdialysis during high $\mathrm{K}^{+}$exposure in leaner and tottering mice. ${ }^{54}$ Thus, $\mathrm{Ca}_{\mathrm{v}} 2.1$-dependent release of glutamate from cortical excitatory synapses appears crucial in determining both initiation and propagation of CSD.

Although the mechanisms for initiation and propagation of CSD are not completely understood, a local increase above a critical value of the $\mathrm{K}^{+}$concentration in the narrow space surrounding cortical neurons and the activation of a sustained net inward current in apical dendrites appear crucial for initiating the positive feedback cycle that almost zeroes the neuronal membrane potential and ignites CSD. ${ }^{48}$ The pivotal role played by both NMDA receptors and $\mathrm{Ca}_{\mathrm{v}} 2.1$ channels in CSD induction and propagation is consistent with a positivefeedback mechanism in which excessive $\mathrm{Ca}_{\mathrm{v}} 2.1$-dependent release of glutamate from synaptic terminals depolarized by high $\mathrm{K}^{+}$and consequent activation of NMDA receptors lead to further depolarization of the postsynaptic membrane, further increase of $\mathrm{K}^{+}$in the extracellular space (that has narrowed, mainly as a consequence of swelling of astrocytes due to $\mathrm{KCl}$ uptake), further release of glutamate, further activation of the NMDA receptor, and so on (see FIG. 5 in Pietrobon ${ }^{2}$ ). The normal brain has efficient regulatory mechanisms, among which the glial uptake mechanisms are particularly important, to keep the extracellular concentration of 


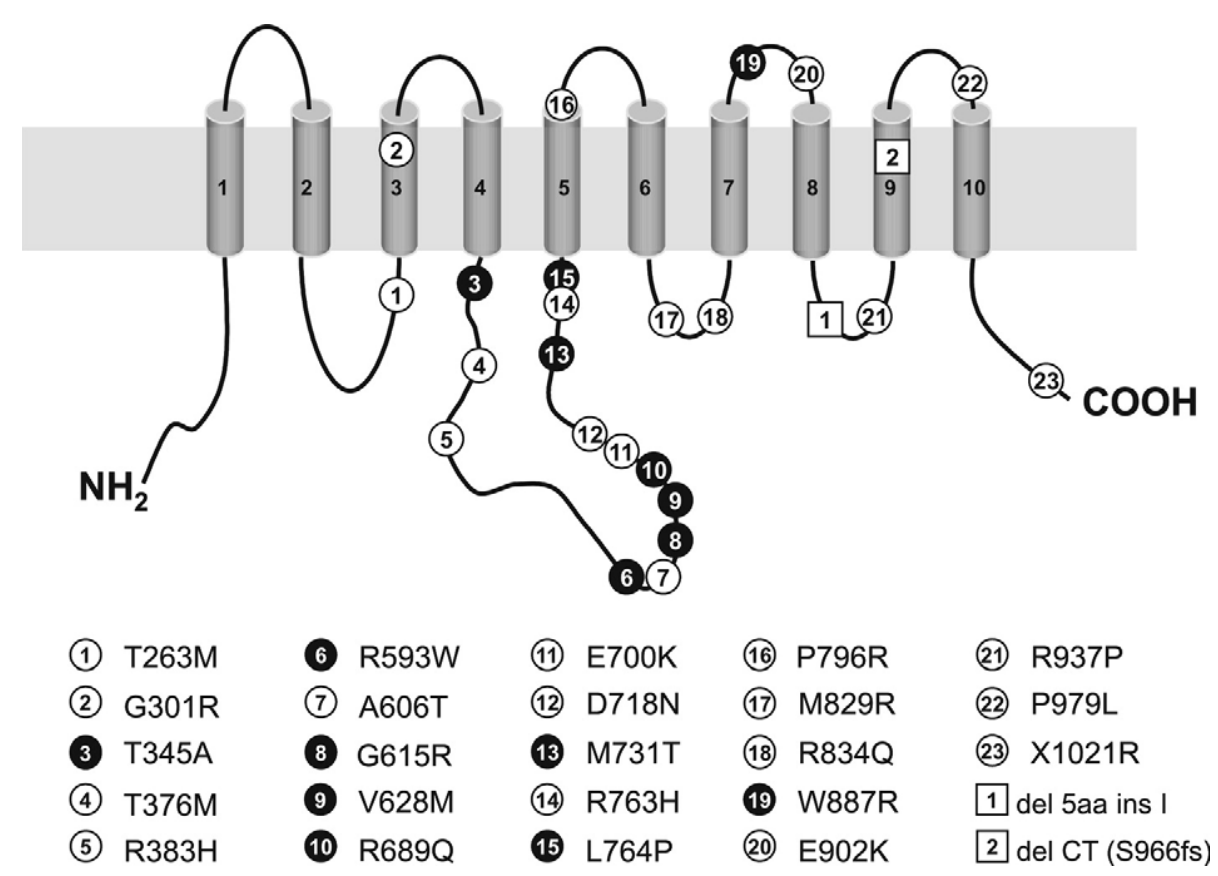

FIG. 2. Secondary structure of the $\mathrm{Na}^{+}, \mathrm{K}^{+}$-ATPase $\alpha_{2}$ subunit and location of the familial hemiplegic migraine 2 mutations identified so far. In black: mutations whose functional consequences have been studied in heterologous expression systems.

$\mathrm{K}^{+}$within the physiologic range during neuronal activity. ${ }^{56}$ The CSD threshold is reached when the regulatory mechanisms that keep the local $\mathrm{K}^{+}$ions concentration in the physiologic range are overwhelmed by the build-up of $\mathrm{K}^{+}$via positive feedback loops. In FHM1 this might occur as a consequence of cortical hyperexcitability due to excessive release of glutamate secondary to increased $\mathrm{Ca}^{2+}$ influx through $\mathrm{Ca}_{\mathrm{v}} 2.1$ channels. Enhanced susceptibility to CSD in FHM1 can be explained, considering that given the lowered voltage threshold for activation of mutant $\mathrm{Ca}_{\mathrm{V}} 2.1$ channels, a lower increase of extracellular $\mathrm{K}^{+}$is necessary to activate synaptic $\mathrm{Ca}_{\mathrm{V}} 2.1$ channels and to release enough glutamate to initiate the positive feedback cycle leading to CSD. Thus, a relatively weak depolarizing stimulus, as a minor head trauma, which is without consequences in healthy individuals, may be able to initiate CSD in FHM1 patients.

Whereas activation of meningeal nociceptors and their sensitization appear crucial for the initiation of migraine pain, self-sustained central sensitization plays a key role in maintaining the severe prolonged pain of migraine headache (Pietrobon and Striessnig, ${ }^{1}$ Pietrobon, ${ }^{2}$ and references therein). Long-term potentiation of nociceptive synapses in the trigeminal nucleus caudalis, with or without alterations of descending endogenous pain modulatory pathways, are plausible hypothetical mechanisms for the maintenance of central sensitization of the trigeminovascular system. ${ }^{1,2,57}$ There is evidence that $\mathrm{Ca}_{\mathrm{v}} 2.1$ channels play an important role in central sensitization in the spinal cord, ${ }^{25,58}$ and that $\mathrm{Ca}_{\mathrm{v}} 2.1$ channels located in the periaqueductal gray region and in the rostroventromedial medulla play a role in de- scending inhibitory and facilitatory pathways that regulate trigeminal and spinal pain. ${ }^{59,60}$ Moreover, $\mathrm{Ca}_{\mathrm{v}} 2.1$ channels are involved in the control of neurotransmitter release from perivascular terminals of meningeal afferents and consequent neurogenic vasodilation. ${ }^{1,61}$ Thus, although the consequences of FHM1 mutations on trigeminal nociception remain unexplored, one may predict alterations that probably lead to hyperexcitability of the nociceptive trigeminovascular pathways in FHM1. This hypothesis can be investigated using the available FHM1 knockin mice.

\section{FAMILIAL HEMIPLEGIC MIGRAINE TYPE 2 (FHM2)}

The gene for FHM2 was identified in 2003 when mutations in ATP1A2, the gene encoding the $\alpha_{2}$ subunit of the $\mathrm{Na}^{+}, \mathrm{K}^{+}$-ATPase, were first demonstrated in two Italian families. ${ }^{10}$ The $\mathrm{Na}^{+}, \mathrm{K}^{+}$-ATPase is a P-type ion pump that utilizes the energy of ATP to actively transport $\mathrm{Na}^{+}$ions out of and $\mathrm{K}^{+}$ions into the cell. It is usually composed of two subunits, a catalytic $\alpha$ subunit, that contains the binding sites for ATP and the cations, and a regulatory $\beta$ subunit. The $\alpha$ subunit consists of 10 membrane spanning segments, with a large 4-5 intracellular loop, which undergoes major conformational changes during the enzymatic cycle and contains the nucleotide-binding domain and phosphorylation site $^{62}$ (FIG. 2). Twenty-three different missense mutations associated with FHM2 have been described, including the R383H SHM mutation (FIG. 2). ${ }^{10,52,63-70}$ All produce substitutions of conserved amino acids in important functional regions including the intracellular 4-5 loop, where 
most of the mutations are located and the extracellular 7-8 loop, a domain responsible for $\beta$ subunit binding. ${ }^{62}$ Two additional mutations associated with FHM2 are deletions, one in frame and one leading to a frameshift and a premature stop $\operatorname{codon}^{67}$ (FIG. 2). FHM2 families often include affected individuals who have a history of seizures and, as with FHM1, some FHM2 patients experience severe episodic neurological deficits such as confusion or impaired consciousness, fever, delayed edema, and permanent mental retardation. ${ }^{19}$ A missense mutation in the ATP1A2 gene (T378N) was also found in two (or one and the same?) families with features that bridge the clinical spectrum between FHM and alternating hemiplegia of childhood (AHC), a rare syndrome characterized by early onset of episodic hemiplegia or quadriplegia with autonomic disturbances, movement disorders, and progressive cognitive impairment. $^{71,72}$

The $\mathrm{Na}^{+}, \mathrm{K}^{+}$-ATPase pumps generate the ion gradients that maintain resting membrane potential and cell volume and provide the driving force for nutrient and neurotransmitter uptake. Glial and neuronal $\mathrm{Na}^{+}, \mathrm{K}^{+}$ATPases play an important role in clearance of $\mathrm{K}^{+}$from the extracellular space during neuronal activity ${ }^{73,74}$ and are fundamental also for the clearance of released glutamate from the synaptic cleft, because active transport of glutamate into astrocytes and neurons is driven by both $\mathrm{Na}^{+}$and $\mathrm{K}^{+}$gradients. Genes encoding four $\alpha \mathrm{Na}^{+}, \mathrm{K}^{+}$ATPase isoforms have been identified. ${ }^{62}$ In contrast with the $\alpha_{1}$ isoform, which maintains generalized cellular homeostasis of $\mathrm{Na}^{+}$and $\mathrm{K}^{+}$as a housekeeping role, the $\alpha_{2}$ isoform plays more specific roles by colocalization with various ion transporters. ${ }^{75}$

In the murine brain, the $\alpha_{2} \mathrm{Na}^{+}, \mathrm{K}^{+}$-ATPase is expressed primarily in neurons during embryonic development and at the time of birth, and primarily in glial cells in the adult. ${ }^{76-78}$ Impaired clearance of neurotransmitters and enhanced neuronal excitation in the amygdala and pyriform cortex were shown in Atp1a2 $2^{-1-}$ mice at the embryonic stage. ${ }^{79}$ These mice die at birth because of lack of spontaneous respiratory activity due to functional impairment of the brainstem respiratory neurons, probably as a result of elevated intracellular $\left[\mathrm{Cl}^{-}\right]$that would switch the GABA response from hyperpolarization to depolarization; the data suggest a specific coupling between the $\alpha_{2} \mathrm{Na}^{+}, \mathrm{K}^{+}$-ATPase and the neuron-specific $\mathrm{K}^{+}-\mathrm{Cl}^{-}$cotransporter, which excludes $\mathrm{Cl}^{-}$ions from the cytosol in respiratory center neurons. ${ }^{80}$ A specific colocalization of the $\alpha_{2}$ isoform of the $\mathrm{Na}^{+}, \mathrm{K}^{+}$pump with the $\mathrm{Na}^{+} / \mathrm{Ca}^{2+}$ exchanger in microdomains that overlie subplasmalemmal endoplasmic reticulum was demonstrated in cultured astrocytes, suggesting a specific functional role of this isoform also in the regulation of intracellular $\mathrm{Ca}^{2+}$, particularly in the endoplasmic reticulum. ${ }^{81}$ Indeed, elevated levels of intracellular $\mathrm{Ca}^{2+}$ ions as well as elevated stores of $\mathrm{Ca}^{2+}$ in the endoplas- mic reticulum were measured in cultured astrocytes from Atp1a2 $2^{-1-}$ mice. ${ }^{82}$ In the adult somatosensory cortex the $\alpha_{2} \mathrm{Na}^{+}, \mathrm{K}^{+}$-ATPase isoform is located exclusively in glial cells and shows a localization virtually identical to that of the astrocytic glutamate transporters GLAST and GLUT1; at the ultrastructural level it appears preferentially localized in astrocytic processes around asymmetrical (glutamatergic) synaptic junctions, and not around GABAergic terminals. ${ }^{78}$ These structural data and previous functional data (e.g., Pellerin and Magistretti ${ }^{83}$ ) are consistent with a specific functional coupling of the $\alpha_{2}$ $\mathrm{Na}^{+}, \mathrm{K}^{+}$-ATPase with astrocytic glutamate transporters and a specific role in glutamate clearance by glial cells during neuronal activity in the adult cortex.

The functional consequences of eight FHM2 mutations (in black, FIG. 2) have been investigated in HeLa cells expressing recombinant (human or rat) $\alpha_{2} \mathrm{Na}^{+}, \mathrm{K}^{+}$ATPase subunits containing mutations that make the pump insensitive to ouabain, which allows one to distinguish the activity of the exogenous pumps from the endogenous pumps of the cell line. ${ }^{10,68,69,84,85}$ Three FHM2 mutations (L764P, W887R, G615R, and also the AHC mutation) produced severe or complete loss-offunction of pump activity, because HeLa cells transfected with the FHM2 mutants showed rapid mortality in the presence of ouabain. ${ }^{10,69,71}$ Complete loss of pump activity (as measured by lack of pump current) with unaltered expression in the plasma membrane has been shown for the L764P and W887R mutants expressed in Xenopus ocytes. ${ }^{86}$ In contrast, the other five FHM2 mutants analyzed so far conferred sufficient $\mathrm{Na}^{+} / \mathrm{K}^{+}$pump activity to allow survival of HeLa cells although at a reduced rate in the case of the R593W and V628M mutants; survival was similar to that conferred by the WT pump in the case of the T345A, M731T, and R689Q mutants. ${ }^{68,84,85}$ However, the T345A mutant had a lower affinity for extracellular $\mathrm{K}^{+}$, which would slow removal of $\mathrm{K}^{+}$from the extracellular space and slow the recovery from neuronal excitation. ${ }^{84}$ The M731T and R689Q mutants had a decreased catalytic turnover and increased affinity for extracellular $\mathrm{K}+$, which would also slow extracellular $\mathrm{K}+$ clearance in the plausible hypothesis that the lower catalytic turnover overrides the effect of increased $\mathrm{K}+$ affinity, at least at high extracellular $\mathrm{K}+$ concentrations. $^{85}$

Impaired clearance of $\mathrm{K}^{+}$and glutamate by astrocytes during cortical neuronal activity, consequent to a decreased number of functional $\mathrm{Na}^{+}, \mathrm{K}^{+}$-ATPases, or a decreased affinity for $\mathrm{K}^{+}$or a decreased catalytic turnover of the $\alpha_{2} \mathrm{Na}^{+}, \mathrm{K}^{+}$-ATPase pumps, would depolarize neurons and enhance glutamate concentration in the synaptic cleft, thus impairing recovery from neuronal excitation. One may predict enhanced susceptibility to CSD in FHM2 considering that relatively weak depolarizing stimuli, that would be without consequences in 
healthy individuals whose efficient glial uptake mechanisms keep the concentration of $\mathrm{K}^{+}$within the physiological range, may be able to produce a local buildup of $\mathrm{K}^{+}$concentration above the critical value that ignites CSD in FHM2 patients with impaired $\mathrm{K}^{+}$and glutamate reuptake mechanisms. The generation of FHM2 knockin mice will allow testing of this prediction.

\section{FAMILIAL HEMIPLEGIC MIGRAINE TYPE 3 (FHM3)}

The gene for FHM3 was identified in 2005, when a mutation in SCN1A, the gene encoding the $\alpha_{1}$ subunit of the voltage-gated $\mathrm{Na}^{+}$channel $\mathrm{Na}_{\mathrm{V}} 1.1$, was identified in three German families. ${ }^{11}$ The pore-forming $\alpha_{1}$ subunit of $\mathrm{Na}_{\mathrm{V}}$ channels shares the fundamental design of six transmembrane segments repeated in four homologous domains, as shown in Figure 1. The FHM3 mutation (Gln1489Lys) is located in the cytoplasmic segment that links domains III and IV, and has been shown to cause accelerated recovery from fast inactivation of recombinant human $\mathrm{Na}_{\mathrm{V}} 1.5$ channels expressed in tsA201 cells, an effect that is predicted to increase neuronal firing rates. ${ }^{11}$ Given the evidence that mutation of the same conserved residue may have different functional effects on different $\mathrm{Na}_{\mathrm{V}}$ channels, ${ }^{87}$ it will be important to confirm this finding in human $\mathrm{Na}_{\mathrm{V}} 1.1$ channels.

$\mathrm{Na}_{\mathrm{V}} 1.1$ channels are expressed primarily in the CNS in late postnatal stages (beginning from the second postnatal week), more in caudal than rostral regions. They are a relatively minor component of total brain $\mathrm{Na}_{\mathrm{V}}$ channels, but are broadly expressed in many types of neurons, including hippocampal and cortical pyramidal cells and inhibitory interneurons, where they appear specifically localized in the soma and proximal dendrites. ${ }^{88,89}$ The specific somatodendritic localization implies that $\mathrm{Na}_{\mathrm{V}} 1.1$ channels may play a key role in mediating dendritic excitability, an important component of synaptic signal processing. ${ }^{90}$ Deletion of the $\mathrm{Na}_{\mathrm{V}} 1.1 \alpha_{1}$ gene had no discernible effect on $\mathrm{Na}^{+}$currents in hippocampal pyramidal neurons of scnala ${ }^{-/-}$mice, but led to $50 \%$ reduction of $\mathrm{Na}^{+}$currents in inhibitory interneurons of heterozygote scnala ${ }^{-/+}$mice, suggesting that $\mathrm{Na}_{\mathrm{V}} 1.1$ channels may be responsible for most or all of the $\mathrm{Na}+$ current in these interneurons, and for a minor fraction of the $\mathrm{Na}^{+}$current in pyramidal cells. ${ }^{89}$ GABAergic interneuron excitability was reduced in both scnala $^{-1-}$ and scnala ${ }^{-/+}$mice, a finding that might underlie the epileptic phenotype of these mice. ${ }^{89}$

This finding has important implications for understanding the pathophysiology of severe myoclonic epilepsy of infancy (SMEI), a rare disorder characterized by early-onset febrile seizures followed by intractable epilepsy, mental deterioration, and ataxia. SMEI is caused by mutations in the SCNAIA gene, most of which are predicted to truncate $\mathrm{Na}_{\mathrm{V}} 1.1$ channels, implying a complete loss of channel function; most of the missense mutations that have been tested functionally in heterologous expression systems produced nonfunctional human $\mathrm{Na}_{\mathrm{v}} 1.1$ channels (although some mutations produced mixed defects, some implying gain-of-function and some loss-of-function of $\mathrm{Na}_{\mathrm{V}} 1.1^{87}$ [and Heron et al. $\left.{ }^{91}\right]$ ). While haploinsufficiency for SCNA1A and consequent reduced excitability of inhibitory neurons might explain seizure susceptibility in most cases of SMEI, the mechanism underlying a milder epileptic disorder (generalized epilepsy with febrile seizures plus: GEFS+), that is caused by missense mutations in SCNAIA leading (in most cases) to gain-of-function alterations in channel activity remains unclear ${ }^{87}$ (see also Heron et al. ${ }^{91}$ ). Considering the high sensitivity of the functional properties of $\mathrm{Na}_{\mathrm{V}}$ channels to the cell background (e.g., compare Cummins et al. ${ }^{92}$ ) and the broad expression of $\mathrm{Na}_{\mathrm{V}} 1.1$ channels in excitatory and inhibitory neurons, one may hypothesize that different types of SCNAIA mutations may affect differently different subpopulations of neurons, as shown in the case of CACNAIA mutations where loss-of-function of $\mathrm{Ca}_{\mathrm{V}} 2.1$ mainly affects cerebellar function, whereas gain-of-function of $\mathrm{Ca}_{\mathrm{v}} 2.1$ mainly affects cortical function.

To test this hypothesis, and in general to understand the pathophysiology of the different SCNAIA channelopathies (including FHM3), it will be essential to analyze neuronal $\mathrm{Na}^{+}$currents, neuronal firing, and neuronal network behavior in knockin mice carrying different SCNAIA mutations. Assuming that the gain-of-function effect of the FHM3 mutation will be confirmed for mutant $\mathrm{Na}_{\mathrm{V}} 1.1$ channels, the knockin mice will also be important to understand how different gain-of- function mutations in the same gene may lead to GEFS + or FHM3, and to understand if and to what extent the two diseases share mechanisms. In this respect, it appears interesting that three out of 18 FHM3 patients had epileptic seizures during infancy. ${ }^{11}$

In a perhaps simplistic view, one may predict enhanced susceptibility to CSD in FHM3, considering that relatively weak depolarizing stimuli that would be without consequences in healthy individuals may produce excessive neuronal firing that might lead to increases in local concentrations of extracellular $\mathrm{K}+$ above the critical value that ignites CSD in FHM3 patients with mutant $\mathrm{Na}_{\mathrm{V}} 1.1$ channels that recover more rapidly from inactivation. The generation of FHM3 scnala knockin mice will allow testing of this prediction.

\section{IMPLICATIONS FOR MIGRAINE MECHANISMS AND TREATMENT}

As mentioned in the Introduction, a major, incompletely understood, issue in the neurobiology of migraine 


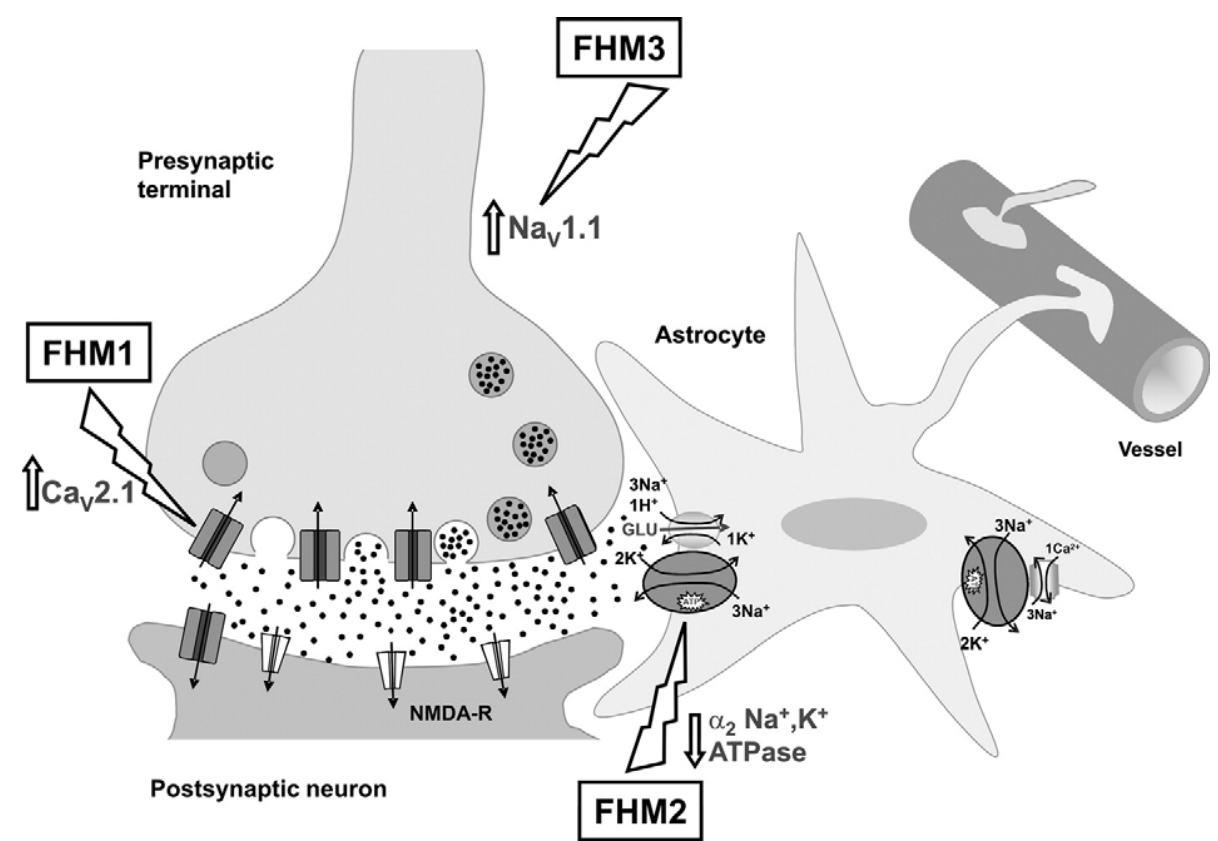

FIG. 3. Gain-of-function mutations in $\mathrm{Ca}_{\mathrm{v}} 2.1$ channels (FHM1) or $\mathrm{Na}_{\mathrm{V}} 1.1$ channels (FHM3) and loss-of-function mutations in $\alpha_{2}$ $\mathrm{Na}^{+}, \mathrm{K}^{+}$-ATPases (FHM2) may all render the brain more susceptible to CSD by causing either excessive synaptic glutamate release (FHM1) or excessive extracellular $\mathrm{K}+(\mathrm{FHM} 3)$ or decreased removal of $\mathrm{K}^{+}$and glutamate from the synaptic cleft (FHM2). Depicted is a glutamatergic synapse. Upon depolarization, glutamate release is controlled by presynaptic $\mathrm{Ca}_{\mathrm{v}} 2.1$ channels. The $\alpha_{2} \mathrm{Na}^{+}, \mathrm{K}^{+}-\mathrm{ATPase}$ is expressed primarily in astrocytes in the adult, where it appears functionally coupled to various transporters (glutamate transporter and $\mathrm{Na} / \mathrm{Ca} 2+$ exchanger in the figure), and plays an important role in clearance of released glutamate and in clearance of $\mathrm{K}^{+}$from the extracellular space during neuronal activity. $\mathrm{Na}_{v} 1.1$ channels are located mainly at the soma and are critical for action potential firing. FHM1 mutations causing gain-of-function of $\mathrm{Ca}_{\mathrm{v}} 2.1$ channels lead to increased synaptic release of glutamate; both FHM2 and FHM3 mutations causing loss-of-function of $\alpha_{2} \mathrm{Na}^{+}, \mathrm{K}^{+}$-ATPase and gain-of-function of $\mathrm{Na}_{\mathrm{v}} 1.1$ channels, respectively, presumably lead to increased glutamate and $\mathrm{K}^{+}$in the synaptic cleft during neuronal activity. In all cases one predicts a lower threshold for initiation of CSD. (ATPase, adenosinetriphosphatase; FHM, familial hemiplegic migraine.)

concerns the nature and mechanisms of the primary brain dysfunction that leads to activation and sensitization of the trigeminovascular system and the ensuing headache. ${ }^{1}$ Much current evidence points to CSD (the phenomenon underlying migraine aura) as a key primary brain dysfunction that may initiate migraine pain, but this idea is still under debate particularly in the case of migraine without aura. ${ }^{1,51,93}$ An alternative view considers migraine aura and headache as parallel, rather than sequential, processes and proposes that the primary cause of migraine headache is an episodic dysfunction in brainstem nuclei involved in the central control of nociception. ${ }^{94}$ The mechanisms that lead to CSD vulnerability and initiate migraine aura remain unknown. While altered cortical excitability in migraineurs has been well documented, whether the cortex is hypo or hyperexcitable is still a matter of debate, although most of the consistent findings point to hyperexcitability. ${ }^{1,95,96}$ The mechanisms that underlie the cortical hyperexcitability and its periodicity remain unknown.

The functional studies of FHM just described support a key role of CSD in migraine pathogenesis. The available data suggest that, most likely FHM1, FHM2, and FHM3 mutations share the ability of rendering the brain more susceptible to CSD by causing either excessive synaptic glutamate release (FHM1) or decreased removal of $\mathrm{K}^{+}$and glutamate from the synaptic cleft (FHM2) or excessive extracellular $\mathrm{K}^{+}$(FHM3) $^{2,39,51,97}$ (FIG. 3). The remarkably overlapping headache phenotype produced by gain-of-function mutations in neuronal $\mathrm{Ca}^{2+}$ and $\mathrm{Na}^{+}$channels, and loss-of-function mutations in astrocytic $\mathrm{Na}^{+}, \mathrm{K}^{+}$ATPases, favors the idea that CSD may initiate migraine attacks and that aura and migraine headache are causally related. The alternative possibility that FHM1, FHM2, and FHM3 mutations alter in a similar manner trigeminovascular pain transmission and its central control appears less likely and remains to be tested.

The FHM data point to ion transport dysfunction as a key factor in determining the brain susceptibility to CSD, and point to cortical hyperexcitability as the basis for vulnerability to CSD and to migraine attacks. Dysfunction of many other channels and transporters, besides $\mathrm{Ca}_{\mathrm{v}} 2.1$ and $\mathrm{Na}_{\mathrm{v}} 1.1$ channels and $\mathrm{Na}^{+}, \mathrm{K}^{+}$-ATPases and also dysfunction of other proteins (e.g., involved in energy supply) may render the brain susceptible to CSD and migraine. The many different molecular mechanisms that can potentially underlie vulnerability to CSD are consistent with the large genetic variability and the complex genetics of migraine and with the highly variable response to prophylactic drugs of migraine patients. 
The FHM data support novel therapeutic strategies that consider CSD and cortical hyperexcitability as key targets of preventive migraine treatment. In this respect, it is very interesting that five migraine prophylactic drugs, belonging to distinct therapeutic classes (valproate, topiramate, amytriptyline, propranolol, and methysergide) and all effective in reducing attack frequency of both MO and MA, have the common property of inhibiting CSD susceptibility after protracted admistration. ${ }^{50}$ The need for protracted administration suggests that changes in gene expression underlies the therapeutic efficacy. In contrast, tonabersat (SB-220453), a benzopyran with anticonvulsant properties currently in phase II clinical trial in the prevention of MA, was found to inhibit CSD after acute administration. ${ }^{98}$ The mechanisms by which these drugs inhibit CSD have not been demonstrated.

Further studies of the incompletely understood mechanisms of initiation and propagation of CSD, and of the changes in gene expression after chronic treatment with current prophylactic drugs, appear important for the development of novel preventive migraine treatment. Even though the FHM genes are probably not involved in common migraines, the study of the cellular mechanisms of enhanced susceptibility to CSD and enhanced cortical excitability in FHM knockin animal models may provide unique insights into possible molecular targets for therapeutic strategies aimed at inhibiting CSD susceptibility and cortical hyperexcitability in migraine. For example, the FHM1 functional studies suggest that drugs capable of shifting the activation range of $\mathrm{Ca}_{\mathrm{v}} 2.1$ channels to more depolarized voltages would make the cortex more resistant to CSD, and may thus be able to prevent migraine with (and possibly also without) aura attacks.

Increased brain excitability most likely underlies the pathophysiology of both migraine and epilepsy, and a common brain state of hyperexcitability could form the basis of comorbidity of migraine with epilepsy. ${ }^{95}$ Indeed, two of the currently most effective migraine prophylactic drugs (topiramate and valproate) are antiepileptics. Understanding the specific cellular and molecular mechanisms leading to hyperexcitability in migraineurs, and what distinguishes them from those in epileptics, will be important for the development of novel specific preventive migraine treatment.

Acknowledgments: I acknowledge support from TelethonItaly (GGP06234), the Italian Ministry of University and Research (Prin2005, FIRB2002), and the European Community (EUROHEAD, LSHM-CT-2004-504837). I gratefully thank Dr. Angelita Tottene for preparation of the figures.

\section{REFERENCES}

1. Pietrobon D, Striessnig J. Neurobiology of migraine. Nat Rev Neurosci 2003;4:386-398.
2. Pietrobon D. Migraine: new molecular mechanisms. Neuroscientist 2005;11:373-386.

3. Wessman M, Kaunisto MA, Kallela M, Palotie A. The molecular genetics of migraine. Ann Med 2004;36:462-473.

4. Kors EE, Vanmolkot KR, Haan J, Frants RR, van den Maagdenberg AM, Ferrari MD. Recent findings in headache genetics. Curr Opin Neurol 2004;17:283-288.

5. Thomsen LL, Eriksen MK, Roemer SF, Andersen I, Olesen J, Russell MB. A population-based study of familial hemiplegic migraine suggests revised diagnostic criteria. Brain 2002;125:13791391.

6. Thomsen LL, Olesen J, Russell MB. Increased risk of migraine with typical aura in probands with familial hemiplegic migraine and their relatives. Eur J Neurol 2003;10:421-427.

7. Ducros A, Denier C, Joutel A, et al. The clinical spectrum of familial hemiplegic migraine associated with mutations in a neuronal calcium channel. N Engl J Med 2001;345:17-24.

8. Ducros A, Joutel A, Vahedi K, et al. Mapping of a second locus for familial hemiplegic migraine to 1q21-q23 and evidence of further heterogeneity. Ann Neurol 1997;42:885-890.

9. Ophoff RA, Terwindt GM, Vergouwe MN, et al. Familial hemiplegic migraine and episodic ataxia type- 2 are caused by mutations in the Ca2 + channel gene CACNL1A4. Cell 1996;87:543-552.

10. De Fusco M, Marconi R, Silvestri L, et al. Haploinsufficiency of ATP1A2 encoding the $\mathrm{Na}+/ \mathrm{K}+$ pump alpha2 subunit associated with familial hemiplegic migraine type 2. Nat Genet 2003;33:192196.

11. Dichgans M, Freilinger T, Eckstein G, et al. Mutation in the neuronal voltage-gated sodium channel SCN1A in familial hemiplegic migraine. Lancet 2005;366:371-377.

12. Thomsen LL, Olesen J. Sporadic hemiplegic migraine. Cephalalgia 2004;24:1016-1023.

13. Kirchmann M, Thomsen LL, Olesen J. The CACNA1A and ATP1A2 genes are not involved in dominantly inherited migraine with aura. Am J Med Genet B Neuropsychiatr Genet 2006;141:250-256.

14. Netzer C, Todt U, Heinze A, et al. Haplotype-based systematic association studies of ATP1A2 in migraine with aura. Am J Med Genet B Neuropsychiatr Genet 2006;141:257-260.

15. Todt U, Dichgans M, Jurkat-Rott K, et al. Rare missense variants in ATP1A2 in families with clustering of common forms of migraine. Hum Mutat 2005;26:315-321.

16. Ambrosini A, D'Onofrio M, Grieco GS, et al. Familial basilar migraine associated with a new mutation in the ATP1A2 gene. Neurology 2005;65:1826-1828.

17. Catterall WA. Structure and regulation of voltage-gated $\mathrm{Ca} 2+$ channels. Annu Rev Cell Dev Biol 2000;16:521-555.

18. Cannon SC. Physiologic Principles Underlying Ion Channelopathies. Neurotherapeutics 2007;4:174-183.

19. Haan J, Kors EE, Vanmolkot KR, van den Maagdenberg AM, Frants RR, Ferrari MD. Migraine genetics: an update. Curr Pain Headache Rep 2005;9:213-220.

20. Dichgans M, Herzog J, Freilinger T, Wilke M, Auer DP. 1H-MRS alterations in the cerebellum of patients with familial hemiplegic migraine type 1. Neurology 2005;64:608-613.

21. Pietrobon D. Function and dysfunction of synaptic calcium channels: insights from mouse models. Curr Opin Neurobiol 2005;15: 257-265.

22. Jun K, Piedras-Renteria ES, Smith SM, et al. Ablation of P/Q-type $\mathrm{Ca} 2+$ channel currents, altered synaptic transmission, and progressive ataxia in mice lacking the a1 A -subunit. Proc Natl Acad Sci U S A 1999;96:15245-15250.

23. Fletcher CF, Tottene A, Lennon VA, et al. Dystonia and cerebellar atrophy in Cacna1a null mice lacking P/Q calcium channel activity. FASEB J 2001;15:1288-1290.

24. Pietrobon D. Calcium channels and channelopathies of the central nervous system. Mol Neurobiol 2002;25:31-50.

25. Luvisetto S, Marinelli S, Panasiti MS, et al. Pain sensitivity in mice lacking the CaV2.1 $\alpha 1$ subunit of P/Q-type Ca2 + channels. Neuroscience 2006;142:823-832.

26. Zhuchenko O, Bailey J, Bonnen P, et al. Autosomal dominant cerebellar ataxia (SCA6) associated with small polyglutamine expansions in the a1A-voltage-dependent calcium channel. Nat Genet 1997;15:62-69. 
27. Imbrici P, Jaffe SL, Eunson LH, et al. Dysfunction of the brain calcium channel CaV2.1 in absence epilepsy and episodic ataxia. Brain 2004;127:2682-2692.

28. Strupp M, Zwergal A, Brandt T. Episodic ataxia type 2. Neurotherapeutics 2007;4:267-273.

29. Kordasiewicz HB, Gomez CM. Molecular pathogenesis of spinocerebellar ataxia type 6 (SCA6). Neurotherapeutics 2007;4:285294.

30. Mullner C, Broos LA, van den Maagdenberg AM, Striessnig J. Familial hemiplegic migraine type 1 mutations K1336E, W1684R, and V1696I alter Cav2.1 Ca2 + channel gating: evidence for beta-subunit isoform-specific effects. J Biol Chem 2004;279:51844-51850

31. Tottene A, Fellin T, Pagnutti S, et al. Familial hemiplegic migraine mutations increase $\mathrm{Ca} 2+$ influx through single human $\mathrm{CaV} 2.1$ channels and decrease maximal CaV2.1 current density in neurons. Proc Natl Acad Sci U S A 2002;99:13284-13289.

32. Kraus RL, Sinnegger MJ, Glossmann H, Hering S, Striessnig J. Familial hemiplegic migraine mutations change a1 A Ca2 + channel kinetics. J Biol Chem 1998;273:5586-5590.

33. Kraus RL, Sinnegger M, Koschak A, et al. Three new familial hemiplegic migraine mutants affect P/Q-type $\mathrm{Ca} 2+$ channel kinetics. J Biol Chem 2000;275:9239-9243.

34. Hans M, Luvisetto S, Williams ME, et al. Functional consequences of mutations in the human a1A calcium channel subunit linked to familial hemiplegic migraine. J Neurosci 1999;19:1610-1619.

35. Tottene A, Pivotto F, Fellin T, Cesetti T, van den Maagdenberg AM, Pietrobon D. Specific kinetic alterations of human CaV2.1 calcium channels produced by mutation S218L causing familial hemiplegic migraine and delayed cerebral edema and coma after minor head trauma. J Biol Chem 2005;280:17678-17686.

36. Melliti K, Grabner M, Seabrook GR. The familial hemiplegic migraine mutation R192Q reduces G-protein-mediated inhibition of P/Q-type $(\mathrm{Ca}(\mathrm{V}) 2.1)$ calcium channels expressed in human embryonic kidney cells. J Physiol 2003;546:337-347.

37. Cao YQ, Piedras-Renteria ES, Smith GB, Chen G, Harata NC, Tsien RW. Presynaptic Ca2+ channels compete for channel typepreferring slots in altered neurotransmission arising from $\mathrm{Ca} 2+$ channelopathy. Neuron 2004;43:387-400.

38. Cao YQ, Tsien RW. Effects of familial hemiplegic migraine type 1 mutations on neuronal P/Q-type Ca2 + channel activity and inhibitory synaptic transmission. Proc Natl Acad Sci U S A 2005; 102:2590-2595.

39. van den Maagdenberg AM, Pietrobon D, Pizzorusso T, et al. A Cacna1a knockin migraine mouse model with increased susceptibility to cortical spreading depression. Neuron 2004;41:701-710.

40. Shapovalova M, Matiello S, Tottene A, van den Maagdenberg AM, Pietrobon D. Calcium channel (CaV2.1) knock-in mice with a familial hemiplegic migraine mutation show an increased calcium current density in cortical pyramidal neurons. Thirty-fourth Annual Meeting of the Society for Neuroscience: October 23-27, 2004; San Diego, CA. Abstract 848.9.

41. Pizzorusso T, Shapovalova M, Gherardini L, et al. Facilitation of neuronal CaV2.1 channels and cortical spreading depression in knockin mice with mutation S218L causing familial hemiplegic migraine and coma after minor head trauma. Thirty-sixth Annual Meeting of the Society for Neuroscience: October 14-18, 2006; Atlanta, GA. Abstract 727.1.

42. Fitzsimons RB, Wolfenden WH. Migraine coma. Meningitic migraine with cerebral oedema associated with a new form of autosomal dominant cerebellar ataxia. Brain 1985;108:555-577.

43. Kors EE, Terwindt GM, Vermeulen FL, et al. Delayed cerebral edema and fatal coma after minor head trauma: role of the CACNA1A calcium channel subunit gene and relationship with familial hemiplegic migraine. Ann Neurol 2001;49:753-760.

44. Curtain RP, Smith RL, Ovcaric M, Griffiths LR. Minor head trauma-induced sporadic hemiplegic migraine coma. Pediatr Neurol 2006;34:329-332.

45. Kaja S, van de Ven RC, Broos LA, et al. Increased transmitter release at neuromuscular synapses of a novel Cacna1a S218L knock-in mouse model for familial hemiplegic migraine. Thirtyfourth Annual Meeting of the Society for Neuroscience: October 23-27, 2004; San Diego, CA. Abstract 593.4.

46. Kaja S, van de Ven RC, Broos LA, et al. Gene dosage-dependent transmitter release changes at neuromuscular synapses of CACNA1A R192Q knockin mice are non-progressive and do not lead to morphological changes or muscle weakness. Neuroscience 2005;135:81-95.

47. Tottene A, Shapovalova M, Frants RR, Ferrari MD, van den Maagdenberg AM, Pietrobon D. Gain-of-function of CaV2.1 calcium channels leads to increased excitatory synaptic transmission in microcultures of cortical neurons from cacnala knockin mice with the R192Q familial hemiplegic migraine mutation. Thirty-fifth Annual Meeting of the Society for Neuroscience: November 12-16, 2005; Washington, DC. Abstract 35.1.

48. Somjen GG. Mechanisms of spreading depression and hypoxic spreading depression-like depolarization. Physiol Rev 2001;81: 1065-1096.

49. Bolay H, Reuter U, Dunn AK, Huang Z, Boas DA, Moskowitz MA. Intrinsic brain activity triggers trigeminal meningeal afferents in a migraine model. Nat Med 2002;8:136-142.

50. Ayata C, Jin H, Kudo C, Dalkara T, Moskowitz MA. Suppression of cortical spreading depression in migraine prophylaxis. Ann Neurol 2006;59:652-661.

51. Sanchez-Del-Rio M, Reuter U, Moskowitz MA. New insights into migraine pathophysiology. Curr Opin Neurol 2006;19:294-298.

52. Dreier JP, Jurkat-Rott K, Petzold GC, et al. Opening of the bloodbrain barrier preceding cortical edema in a severe attack of FHM type II. Neurology 2005;64:2145-2147.

53. Gursoy-Ozdemir Y, Qiu J, Matsuoka N, et al. Cortical spreading depression activates and upregulates MMP-9. J Clin Invest 2004; 113:1447-1455.

54. Ayata C, Shimizu-Sasamata M, Lo EH, Noebels JL, Moskowitz MA Impaired neurotransmitter release and elevated threshold for cortical spreading depression in mice with mutations in the a1A subunit of P/Q type calcium channels. Neuroscience 2000;95:639-645.

55. Marrannes R, Willems R, De Prins E, Wauquier A. Evidence for a role of the N-methyl-D-aspartate (NMDA) receptor in cortical spreading depression in the rat. Brain Res 1988;457:226-240.

56. Somjen GG. Ion regulation in the brain: implications for pathophysiology. Neuroscientist 2002;8:254-267.

57. Knight YE, Goadsby PJ. The periaqueductal grey matter modulates trigeminovascular input: a role in migraine? Neuroscience 2001; 106:793-800.

58. Vanegas H, Schaible H. Effects of antagonists to high-threshold calcium channels upon spinal mechanisms of pain, hyperalgesia and allodynia. Pain 2000;85:9-18.

59. Knight YE, Bartsch T, Kaube H, Goadsby PJ. P/Q-type calciumchannel blockade in the periaqueductal gray facilitates trigeminal nociception: a functional genetic link for migraine? J Neurosci 2002; 22:RC213

60. Urban MO, Ren K, Sablad M, Park KT. Medullary N-type and $\mathrm{P} / \mathrm{Q}$-type calcium channels contribute to neuropathy-induced allodynia. Neuroreport 2005;16:563-566.

61. Akerman S, Williamson DJ, Goadsby PJ. Voltage-dependent calcium channels are involved in neurogenic dural vasodilatation via a presynaptic transmitter release mechanism. Br J Pharmacol 2003; 140:558-566.

62. Jorgensen PL, Hakansson KO, Karlish SJ. Structure and mechanism of Na,K-ATPase: functional sites and their interactions. Annu Rev Physiol 2003;65:817-849.

63. Vanmolkot KR, Kors EE, Hottenga JJ, et al. Novel mutations in the $\mathrm{Na}+, \mathrm{K}+$-ATPase pump gene ATP1A2 associated with familial hemiplegic migraine and benign familial infantile convulsions. Ann Neurol 2003;54:360-366.

64. Kaunisto MA, Harno H, Kallela M, et al. Novel splice site CACNA1A mutation causing episodic ataxia type 2 . Neurogenetics 2004;5:69-73.

65. Spadaro M, Ursu S, Lehmann-Horn F, et al. A G301R Na(+)/ $\mathrm{K}(+)$-ATPase mutation causes familial hemiplegic migraine type 2 with cerebellar signs. Neurogenetics 2004;5:177-185.

66. Jurkat-Rott K, Freilinger T, Dreier JP, et al. Variability of familial hemiplegic migraine with novel A1A2 Na+/K+-ATPase variants. Neurology 2004;62:1857-1861.

67. Riant F, De Fusco M, Aridon P, et al. ATP1A2 mutations in 11 families with familial hemiplegic migraine. Hum Mutat 2005;26:281. 
68. Vanmolkot KR, Kors EE, Turk U, et al. Two de novo mutations in the Na,K-ATPase gene ATP1A2 associated with pure familial hemiplegic migraine. Eur J Hum Genet 2006;14:555-560.

69. Vanmolkot KR, Stroink H, Koenderink JB, et al. Severe episodic neurological deficits and permanent mental retardation in a child with a novel FHM2 ATP1A2 mutation. Ann Neurol 2006;59:310-314.

70. Pierelli F, Grieco GS, Pauri F, et al. A novel ATP1A2 mutation in a family with FHM type II. Cephalalgia 2006;26:324-328.

71. Bassi MT, Bresolin N, Tonelli A, et al. A novel mutation in the ATP1A2 gene causes alternating hemiplegia of childhood. J Med Genet 2004;41:621-628.

72. Swoboda KJ, Kanavakis E, Xaidara A, et al. Alternating hemiplegia of childhood or familial hemiplegic migraine? A novel ATP1A2 mutation. Ann Neurol 2004;55:884-887.

73. D'Ambrosio R, Gordon DS, Winn HR. Differential role of KIR channel and $\mathrm{Na}(+) / \mathrm{K}(+)$-pump in the regulation of extracellular $\mathrm{K}(+)$ in rat hippocampus. J Neurophysiol 2002;87:87-102.

74. Ransom CB, Ransom BR, Sontheimer H. Activity-dependent extracellular $\mathrm{K}+$ accumulation in rat optic nerve: the role of glial and axonal Na+ pumps. J Physiol 2000;522:427-442.

75. Lingrel J, Moseley A, Dostanic I, et al. Functional roles of the alpha isoforms of the Na,K-ATPase. Ann N Y Acad Sci 2003;986: 354-359.

76. Moseley AE, Lieske SP, Wetzel RK, et al. The Na,K-ATPase alpha 2 isoform is expressed in neurons, and its absence disrupts neuronal activity in newborn mice. J Biol Chem 2003;278:53175324.

77. McGrail KM, Phillips JM, Sweadner KJ. Immunofluorescent localization of three $\mathrm{Na}, \mathrm{K}-\mathrm{ATPase}$ isozymes in the rat central nervous system: both neurons and glia can express more than one Na,K-ATPase. J Neurosci 1991;11:381-391.

78. Cholet N, Pellerin L, Magistretti PJ, Hamel E. Similar perisynaptic glial localization for the $\mathrm{Na}+, \mathrm{K}+$-ATPase alpha 2 subunit and the glutamate transporters GLAST and GLT-1 in the rat somatosensory cortex. Cereb Cortex 2002;12:515-525.

79. Ikeda K, Onaka T, Yamakado M, et al. Degeneration of the amygdala/piriform cortex and enhanced fear/anxiety behaviors in sodium pump alpha2 subunit (Atp1a2)-deficient mice. J Neurosci 2003;23:4667-4676.

80. Ikeda K, Onimaru H, Yamada J, et al. Malfunction of respiratoryrelated neuronal activity in $\mathrm{Na}+, \mathrm{K}+$-ATPase alpha2 subunitdeficient mice is attributable to abnormal $\mathrm{Cl}$ - homeostasis in brainstem neurons. J Neurosci 2004;24:10693-10701.

81. Juhaszova M, Blaustein MP. Na+ pump low and high ouabain affinity alpha subunit isoforms are differently distributed in cells. Proc Natl Acad Sci U S A 1997;94:1800-1805.

82. Golovina VA, Song H, James PF, Lingrel JB, Blaustein MP. Na+ pump alpha 2-subunit expression modulates $\mathrm{Ca} 2+$ signaling. Am $\mathrm{J}$ Physiol Cell Physiol 2003;284:C475-486.

83. Pellerin L, Magistretti PJ. Glutamate uptake stimulates $\mathrm{Na}+, \mathrm{K}+$ -
ATPase activity in astrocytes via activation of a distinct subunit highly sensitive to ouabain. J Neurochem 1997;69:2132-2137.

84. Segall L, Scanzano R, Kaunisto MA, et al. Kinetic alterations due to a missense mutation in the $\mathrm{Na}, \mathrm{K}-\mathrm{ATPase}$ alpha2 subunit cause familial hemiplegic migraine type 2. J Biol Chem 2004;279:43692-43696.

85. Segall L, Mezzetti A, Scanzano R, Gargus JJ, Purisima E, Blostein $\mathrm{R}$. Alterations in the alpha2 isoform of $\mathrm{Na}, \mathrm{K}-\mathrm{ATPase}$ associated with familial hemiplegic migraine type 2. Proc Natl Acad Sci U S A 2005;102:11106-11111.

86. Koenderink JB, Zifarelli G, Qiu LY, et al. Na,K-ATPase mutations in familial hemiplegic migraine lead to functional inactivation. Biochim Biophys Acta 2005;1669:61-68.

87. Meisler MH, Kearney JA. Sodium channel mutations in epilepsy and other neurological disorders. J Clin Invest 2005;115:20102017.

88. Gong B, Rhodes KJ, Bekele-Arcuri Z, Trimmer JS. Type I and type II $\mathrm{Na}(+)$ channel alpha-subunit polypeptides exhibit distinct spatial and temporal patterning, and association with auxiliary subunits in rat brain. J Comp Neurol 1999;412:342-352.

89. Yu FH, Mantegazza M, Westenbroek RE, et al. Reduced sodium current in GABAergic interneurons in a mouse model of severe myoclonic epilepsy in infancy. Nat Neurosci 2006;9:1142-1149.

90. Johnston D, Magee JC, Colbert CM, Cristie BR. Active properties of neuronal dendrites. Annu Rev Neurosci 1996;19:165-186.

91. Heron SE, Scheffer IE, Berkovic SF, Dibbens LM, Mulley JC. Channelopathies in idiopathic epilepsy. Neurotherapeutics 2007;4: 295-304.

92. Cummins TR, Aglieco F, Renganathan M, Herzog RI, Dib-Hajj SD, Waxman SG. Nav1.3 sodium channels: rapid repriming and slow closed-state inactivation display quantitative differences after expression in a mammalian cell line and in spinal sensory neurons. J Neurosci 2001;21:5952-5961.

93. Goadsby PJ. Migraine, aura, and cortical spreading depression: why are we still talking about it? Ann Neurol 2001;49:4-6.

94. May A, Goadsby PJ. The trigeminovascular system in humans: pathophysiologic implications for primary headache syndromes of the neural influences on the cerebral circulation. J Cereb Blood Flow Metab 1999;19:115-127.

95. Welch KM. Brain hyperexcitability: the basis for antiepileptic drugs in migraine prevention. Headache 2005;45(suppl 1):S25-32.

96. Ambrosini A, Schoenen J. The electrophysiology of migraine. Curr Opin Neurol 2003;16:327-331.

97. Moskowitz MA, Bolay H, Dalkara T. Deciphering migraine mechanisms: clues from familial hemiplegic migraine genotypes. Ann Neurol 2004;55:276-280.

98. Smith MI, Read SJ, Chan WN, et al. Repetitive cortical spreading depression in a gyrencephalic feline brain: inhibition by the novel benzoylamino-benzopyran SB-220453. Cephalalgia 2000;20:546553. 